\title{
Use of unabsorbed radioactive marker substances in a re-assessment of the radioactive triolein test of fat absorption
}

\author{
R. K. DITCHBURN, A. H. SMITH, AND C. J. HAYTER
}

From the Department of Nuclear Medicine, The General Infirmary at Leeds

SYNOPSIS The radioactive triolein test has been compared with two chemical methods for the assessment of fat absorption in a group of inpatients from general medical wards. The special feature of the investigation is the use of a radioactive faecal marker to measure the completeness of 0 faecal collections during the investigation period. Estimations of unabsorbed ${ }^{131}$ I triolein and faecal fat measured by the chemical methods were made on the same specimens.

The results showed that only $48 \%$ of the patients provided a complete collection of faeces (defined as a recovery of more than $90 \%$ of the faecal marker). From these patients good correlations were found between the triolein absorption test and the two chemical methods.

It is suggested that previous criticism of the radioactive triolein test may have been due to incomplete faecal collections causing false results.

The use of radioactive-labelled fats in the study of fat absorption was first described by Stanley and Thannhauser in 1949. They suggested that after the oral administration of labelled fat an index of absorption could be obtained from a measurement of either the subsequent blood radioactivity curve or the amount of unabsorbed radioactivity in the faeces. After initial enthusiasm (Baylin, Sanders, Isley, Shingleton, Hymans, Johnston, and Ruffin, 1955; Ruffin, Shingleton, Baylin, Hymans, Isley, Sanders, and Sohmer, 1956; Ruffin, Keever, Chears, Shingleton, Baylin, Isley, and Sanders, 1958) the use of the blood curve has been rejected by most investigators because its peak and shape were shown to be influenced by factors other than that due to fat absorption (Isley, Sanders, Baylin, Sharpe, Hymans, Ruffin, Shingleton, and Wilson, 1957; Mohamed and Hume, 1959; and Vidinli, Texter, and Cooper, 1963). More recently, the use of the measurement of faecal radioactivity after oral administration of labelled fat has also fallen into disrepute, chiefly because several workers found inconsistent correlation with chemical faecal fat estimation (eg, Pimparkar, Tulsky, Kalser, and Bockus, 1960; Cox, 1961; Clark, Crooks, Dawson, and Mitchell, 1964).

In this report a new attempt has been made to correlate the measurement of faecal radioactivity after the oral administration of ${ }^{131}$ I-labelled triolein, Received for publication 29 October 1970. faecal fat using the chemical method of van de Kamer, Huinink, and Weijers (1949), and total faecal lipid measured gravimetrically after extraction $\frac{O}{\mathbb{Q}}$ of the whole faecal homogenate. A special feature of 0 the series is the use of faecal markers to correct for $\overline{\vec{a}}$ any loss of faeces during the investigation as it has been suggested, although not tested, that part of the unreliability of the test might be due to a failure to obtain a complete faecal collection. In order to confirm that complete faecal recovery had been achieved, an unabsorbed radioactively labelled marker substance

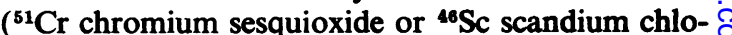
ride) was given orally together with the ${ }^{131} \mathrm{I}$-labelled $₹$ triolein. It was shown that the marker and the un- o absorbed fat pass through the gut at the same rate. Therefore the amount of marker radioactivity recovered as a percentage of the administered amount indicates the percentage recovery of the activity ? corresponding to the radioactive triolein. Two $N$ methods for the estimation of faecal fat were used $\underset{\mathrm{W}}{\mathrm{S}}$ as it is also possible that the discrepancies between $O$ radioactive fat absorption tests and faecal fat measured by chemical means are due to the chemical estimation techniques. The usual method (van de $\stackrel{\oplus}{\rightarrow}$ Kamer et al, 1949) involves titration for fatty acids 0 after saponification, acidification, and extraction ${ }_{0}^{\circ}$ from a small aliquot of faecal homogenate. Possible $\stackrel{\mathbb{\Phi}}{\rho}$ errors in this method include those inherent in the $\frac{?}{\mathbb{D}}$ taking of small samples and those due to the 
assumption of a mean molecular weight for faecal fatty acids (Andersen, 1945).

\section{Materials and Methods}

Eighty-three inpatients from general medical wards were used in this investigation. They consisted of $\mathbf{3 1}$ patients with known gastrointestinal disorders of various kinds (not necessarily associated with steatorrhoea) and 52 patients without known gastrointestinal disease ('normals'). The object of the investigation was explained to each of them, and all agreed to take part.

A standard procedure was adopted for the administration of tracer substances and for the subsequent collection of faeces. All patients received an oral dose of marker $\left({ }^{51} \mathrm{Cr}\right.$-chromium sesquioxide or ${ }^{46} \mathrm{Sc}$ scandium chloride) but only 62 of them received both marker and ${ }^{131}$ I-labelled triolein. Each patient was allowed a normal ward diet before and during the test but no attempt was made to measure the actual quantity eaten. The daily fat content of the diet was estimated to be between 80 and $120 \mathrm{~g}$ per day.

The radioactive triolein was obtained from the Radiochemical Centre, Amersham. It was stated to have been iodinated to $20 \%$ completion using iodine monochloride ${ }^{131}$ I. Free ${ }^{131}$ I content was stated to be less than $1 \%$ of the total. Chromium sesquioxide${ }^{51} \mathrm{Cr}$ was used initially as the faecal marker; gelatin capsules containing $0.5 \mathrm{~g}$ chromium sesquioxide were irradiated at U.K.A.E.A., Harwell, to provide the ${ }^{51} \mathrm{Cr}$ label. The absence of radioactive impurities was confirmed by monitoring samples using a sodium iodide crystal detector and a calibrated multichannel analyser. The radioactivity contained in each capsule was determined by comparison with a reference source of known strength.

Later, labelled chromium sesquioxide was replaced as the marker by scandium chloride- ${ }^{16} \mathrm{Sc}$, because of the technical advantages (see Appendix). To confirm that ${ }^{16} \mathrm{Sc}$ is not significantly absorbed from the gastrointestinal tract, two patients were each given $1 \cdot 1 \mu \mathrm{Ci}{ }^{46} \mathrm{Sc}$-scandium chloride solution orally, and then body radioactivity was measured over a period of time in a whole body counter ${ }^{1}$. Total urinary excretion of ${ }^{46} \mathrm{Sc}$ was also measured.

The radioactive materials were given immediately before the patient's midday meal. When both labelled triolein and labelled marker were given they were taken simultaneously. The ${ }^{131}$ I-triolein was dissolved in olive oil, and a few drops, containing 3-5 $\mu \mathrm{Ci}$, were administered on a slice of bread. The drops were dispensed from a syringe, and the actual

'M.R.C. Environmental Radiation Unit, Department of Medical Physics, University of Leeds. dose received was calculated from the difference of weight of the syringe. For the faecal marker, either a gelatin capsule containing $5-10 \mu \mathrm{Ci}{ }^{51} \mathrm{Cr}$ chromium sesquioxide was swallowed, or approximately $50 \mu \mathrm{g}$ scandium chloride containing $100 \mathrm{nCi}^{46} \mathrm{Sc}$ in $10 \mathrm{ml}$ water was dispensed into a wax cup and drunk together with several rinsings. Precise measurement of the activity drunk was obtained by measuring the activity in the cup before and after drinking.

Faeces were collected for five days. If the patient was passing motions infrequently collection was continued until the activity in successive motions became negligible. Where the motions were very frequent and bulky (due to steatorrhoea or diarrhoea from other causes) faecal collection was terminated on the same basis and could last as little as two days. Each stool was stored in a separate polyethylene container, and the collected specimens were stored at $-12^{\circ} \mathrm{C}$. Patients were instructed to avoid contaminating the faeces with urine.

\section{RADIOACTIVE ANALYSIS}

The radioactivity in each container was measured using a large volume $4 \pi$ plastic scintillation detector (Smith, Clarke, and Reed, 1967). The proportion of the total radioactivity due to the respective isotopes was calculated in the normal manner by measuring the count rate from each container at two pulse height analyser window settings and comparing them against standard activities of ${ }^{131} \mathrm{I}$ and ${ }^{51} \mathrm{Cr}$ (or ${ }^{46} \mathrm{Sc}$ ). All stools from the beginning of the collection period were counted until two successive stools each contained less than $1 \%$ of the administered activity of each isotope. The cumulative counts for each isotope were then expressed as percentages of the administered dose.

\section{CHEMICAL ANALYSIS}

The same collections were used for chemical faecal fat analysis. The whole faecal collection from each individual was bulked together and homogenized with water to give a volume of between 1.5 and 3.01 dependent upon the original volume and consistency of the faeces.

\section{Method $A$}

A $20 \mathrm{ml}$ aliquot of the homogenate was removed immediately after homogenization for analysis of fat content by the method of van de Kamer et al (1949).

\section{Method B}

The whole of the remaining homogenate was boiled for 30 minutes with concentrated hydrochloric acid (150 ml per litre of homogenate) to break up any large particles and to convert soaps into fatty acids, 


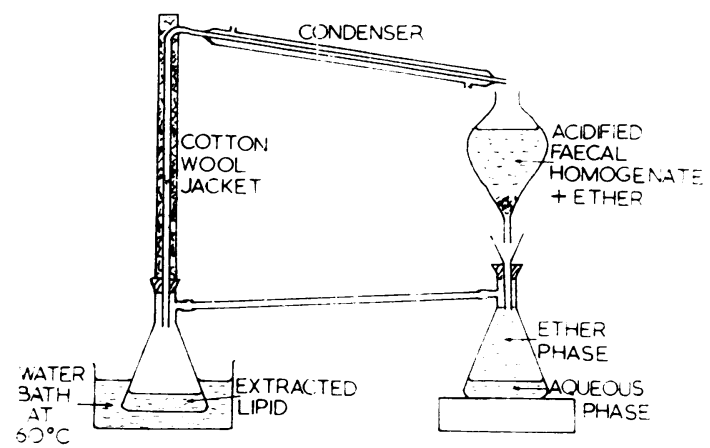

Fig. 1 Schematic diagram of the apparatus used to extract total lipid from faecal homogenate.

It was then shaken for five minutes in a large separating flask with a 1:4 mixture of diethyl ether and light petroleum ether (BP $40-60^{\circ} \mathrm{C}$ ) (Zuckerman, Zymaris, and Natelson, 1949; Henry, 1964). Continuous extraction was then carried out in the apparatus shown in Figure 1. Extraction took eight hours or longer and was continued until one hour after the ether leaving the faecal residue container became colourless. The faecal residue was intermittently stirred during extraction. After extraction the ether was evaporated from the lipid which was then weighed after drying to constant weight in a vacuum over anhydrous calcium chloride.

In order to test the efficiency of extraction, aliquots of several of the dried faecal residues were reextracted for six hours in a Soxhlet apparatus. The small quantities of lipid recovered in this way showed that more than $99 \%$ of the fat soluble in the solvent system used must have been removed.

In the following sections the faecal fat measured by method $A$ will be called fat $A$ and that by method $B$ will be called fat $B$.

\section{Results}

All of the 83 patients in whom faecal collection was attempted were given a radioactive marker. In $\mathbf{4 0}$ the marker was ${ }^{51} \mathrm{Cr}$-chromium sesquioxide and in 43 it was ${ }^{46} \mathrm{Sc}$-scandium chloride. The excretion rates of the two marker substances were identical. The completeness of faecal collection was judged from the recovery of the marker in the faeces; the amounts are shown in Figure 2. They varied from less than $10 \%$ ( 8 cases) to between 100 and $110 \%$ (16 cases). The values higher than $100 \%$ are presumed to be the result of cumulative errors in counting faecal radioactivity. Collections giving recovery values of more than $90 \%$ were taken as "complete

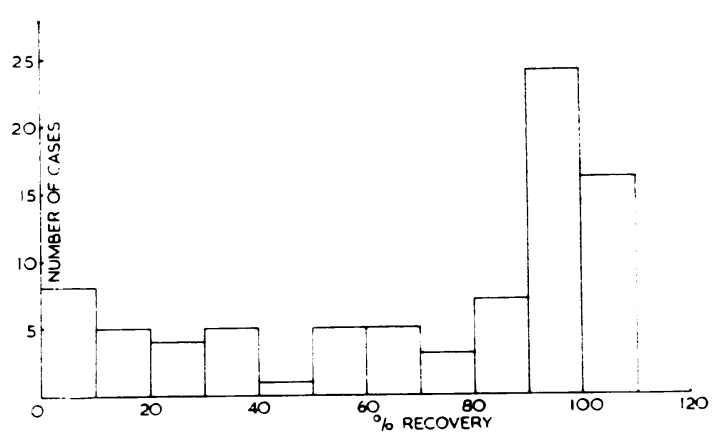

Fig. 2 Histogram showing the recovery of faecal marker over the collection period in 83 cases.

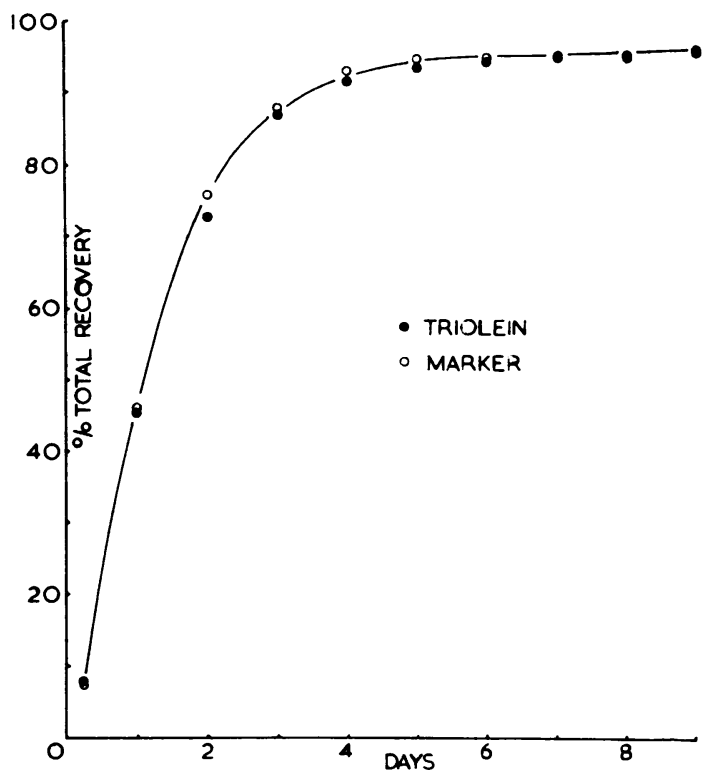

Fig. 3 The cumulative faecal recovery of marker and faecal triolein vs time in 33 cases with complete marker recovery. On each date the cumulative amount of each isotope recovered is expressed as a percentage of the recovery over the whole collection period.

collections': there were 40 of these. However, only 33 patients received both marker and ${ }^{131}$ I-triolein. The mean cumulative recovery rates of marker $\left({ }^{51} \mathrm{Cr}\right.$ and $\left.{ }^{46} \mathrm{Sc}\right)$ and ${ }^{131}$ I-triolein are compared in $\stackrel{\mathscr{P}}{?}$ Figure 3.

Of these 33 patients, 15 were normal and 18 had gastrointestinal disorders. The results of the estimations of fat A, fat B, and faecal ${ }^{131}$ I-triolein in the normal group are summarized in Table $I$. The upper 
limit of the normal range (mean $+2 \mathrm{SD}$ ) is taken as $6.8 \mathrm{~g} /$ day for fat $\mathrm{A}, 9.2 \mathrm{~g} /$ day for fat $\mathrm{B}$, and $2.5 \%$ of administered dose for ${ }^{131}$ I-triolein. Individual

\begin{tabular}{llll}
\hline & $\begin{array}{l}\text { Fat A } \\
(\mathrm{g} / \text { day })\end{array}$ & $\begin{array}{l}\text { Fat B } \\
(\mathrm{g} / \text { day })\end{array}$ & $\begin{array}{l}121 \text { I-Triolein } \\
(\% \text { dose })\end{array}$ \\
\hline Mean & $3 \cdot 53$ & $5 \cdot 25$ & $1 \cdot 5$ \\
Observed range & $1 \cdot 33-6.37$ & $2 \cdot 18-8.07$ & $0 \cdot 6-2 \cdot 2$ \\
SD & $1 \cdot 64$ & 1.96 & $0 \cdot 5$ \\
Mean + 2 SD & $6 \cdot 81$ & $9 \cdot 17$ & $2 \cdot 5$ \\
\hline
\end{tabular}

Table I Results in 15 normal cases with marker recovery of $90 \%$ or greater

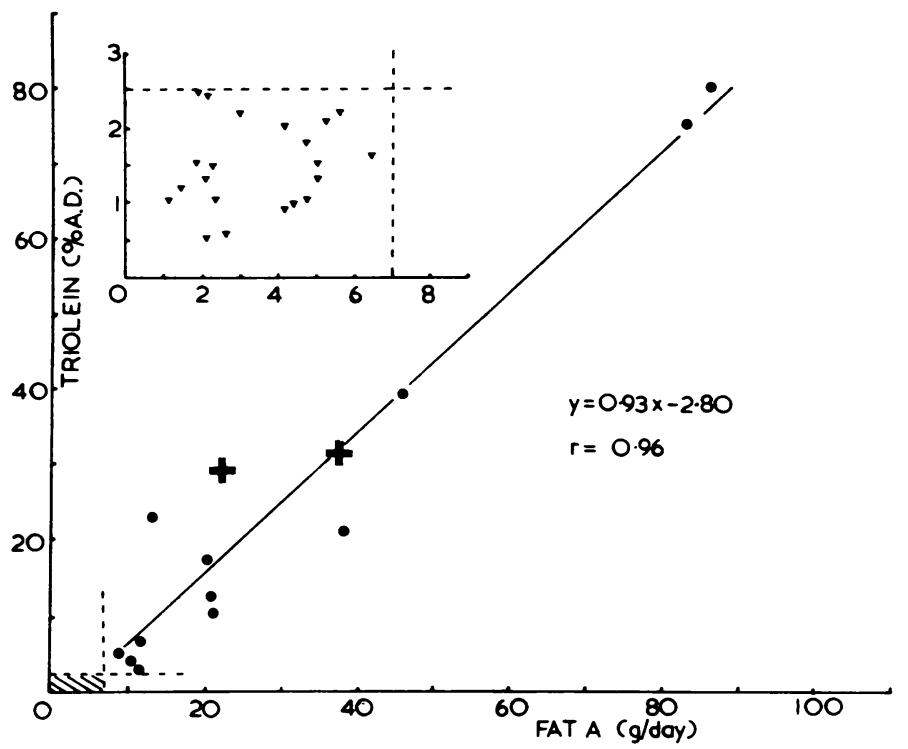

\section{Fig. 4 Relationship between faecal triolein (percentage of administered dose) and faecal fat (g/day) for (a) fat $A$ and (b) fat $B$. + These cases had a faecal recovery between $85 \%$ and $90 \%$. All other cases had a faecal marker recovery greater than $90 \%$.}

Fig. 4a.

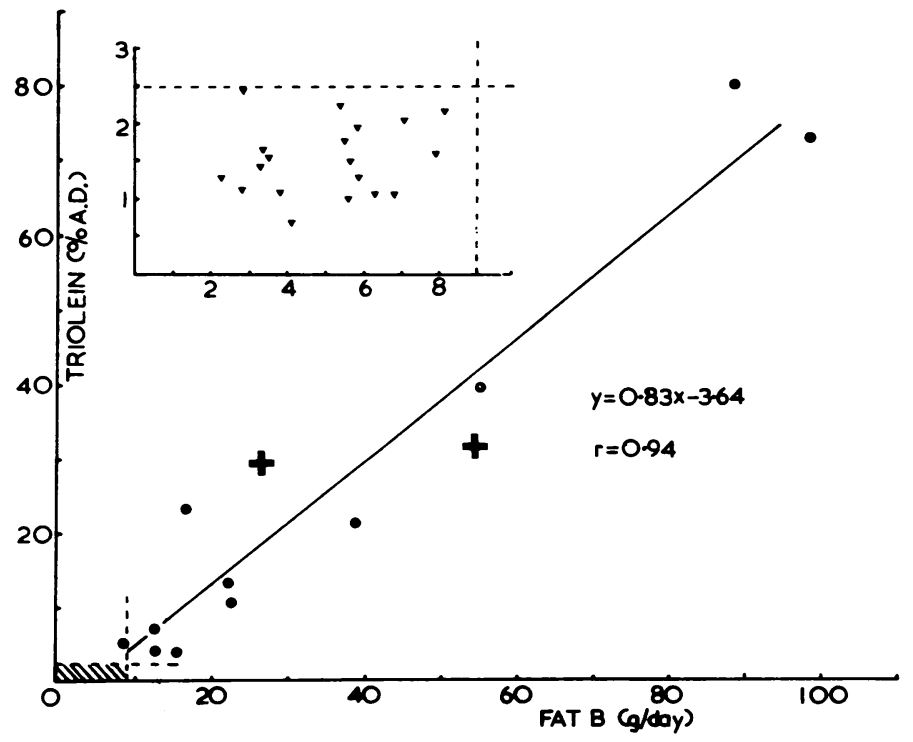

Fig. 4b. 


\begin{tabular}{|c|c|c|c|c|}
\hline Case & Diagnosis & $\begin{array}{l}\text { Fat } A \\
(g / d a y)\end{array}$ & $\begin{array}{l}\text { Fat } B \\
(g / \text { day })\end{array}$ & $\begin{array}{l}131 \text {-triolein } \\
(\% \text { dose) }\end{array}$ \\
\hline $\begin{array}{l}1 \\
2 \\
3 \\
4 \\
5 \\
6 \\
7 \\
8 \\
9 \\
10 \\
11 \\
12 \\
13 \\
14 \\
15 \\
16 \\
17 \\
18\end{array}$ & $\begin{array}{l}\text { Partial gastrectomy } \\
\text { 'Functional' diarrhoea } \\
\text { Partial gastrectomy } \\
\text { Partial gastrectomy } \\
\text { Gluten-sensitive enteropathy } \\
\text { Partial gastrectomy } \\
\text { Biliary cirrhosis } \\
\text { Biliary cirrhosis } \\
\text { Partial gastrectomy } \\
\text { Partial gastrectomy } \\
\text { Obstructive jaundice } \\
\text { Total gastrectomy } \\
\text { Crohn's + resection } \\
\text { Partial gastrectomy } \\
\text { Chronic pancreatitis } \\
\text { Crohn's + resection } \\
\text { Crohn's + resection } \\
\text { Crohn's + resection }\end{array}$ & $\begin{array}{l}1 \cdot 07 \\
1 \cdot 87 \\
2 \cdot 09 \\
2 \cdot 47 \\
4 \cdot 99 \\
5 \cdot 00 \\
8 \cdot 52 \\
11 \cdot 05 \\
11 \cdot 52 \\
10 \cdot 52 \\
13 \cdot 11 \\
17 \cdot 05 \\
20 \cdot 00 \\
20.96 \\
38 \cdot 1 \\
45 \cdot 8 \\
83 \cdot 5 \\
86 \cdot 52\end{array}$ & $\begin{array}{l}2 \cdot 76 \\
2 \cdot 75 \\
- \\
4 \cdot 02 \\
5 \cdot 55 \\
5 \cdot 80 \\
8 \cdot 47 \\
12 \cdot 31 \\
15 \cdot 08 \\
12 \cdot 41 \\
16 \cdot 42 \\
22 \cdot 11 \\
-7 \\
22 \cdot 40 \\
39 \cdot 05 \\
54 \cdot 9 \\
98 \cdot 74 \\
88 \cdot 6\end{array}$ & $\begin{array}{r}1 \cdot 1 \\
2 \cdot 4 \\
2 \cdot 4 \\
0 \cdot 7 \\
1 \cdot 5 \\
1 \cdot 3 \\
5 \cdot 0 \\
7 \cdot 0 \\
2 \cdot 7 \\
4 \cdot 2 \\
23 \cdot 0 \\
12 \cdot 8 \\
17 \cdot 8 \\
10 \cdot 4 \\
21 \cdot 2 \\
39 \cdot 4 \\
75 \cdot 4 \\
80 \cdot 2\end{array}$ \\
\hline
\end{tabular}

Table II Results in 18 cases with diseases associated with gastrointestinal disorders with marker recovery of $90 \%$ or greater

exception (case 7, Table II), where fat $\mathrm{B}$ gave a value at the upper end of the normal range although fat $A$ and ${ }^{131}$ I-triolein values were clearly abnormal. In abnormal cases there is good correlation between the triolein method and the fat A method $(r=0.96)$, and also between the triolein method and the fat $B$ method $(r=0.94)$. In normal cases, however, no such correlation is seen.

Values for fat $A$ and fat $B$, estimated from the same homogenate in each of the 31 complete collections (plus the two $85-90 \%$ collections referred to above), are compared in Figure 5a and b. In the 20 with results within the normal range the mean ratio fat

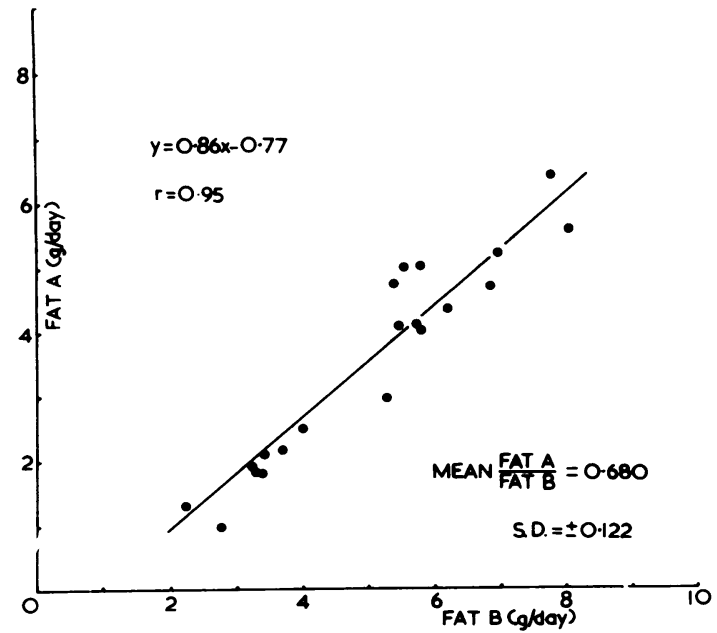

Fig. 5a.
$\mathrm{A} /$ fat $\mathrm{B}$ was $0.68 \pm 0.12$ and in the 13 with abnormal results it was $0.87 \pm 0.09$. Variation of the ratios for individual cases in the normal group is large (range 0.38-0.91) but in the abnormal group the range is small $(0 \cdot 70-0.95)$.

In two patients given ${ }^{46} \mathrm{Sc}$-scandium chloride and in whom body retention and urine excretion of ${ }^{46} \mathrm{Sc}$ was measured, $0.85 \pm 0.1 \%$ and $0.66 \pm 0.1 \%$ क respectively was retained at the end of seven days, $\overrightarrow{0}$ and in each the cumulative urinary excretion was less than $0.5 \%$.

\section{Discussion}

The upper limits (mean +2 SD) of the normal of range for faecal fat and ${ }^{131}$ I-triolein from these data $O$ may be compared in Table III with those adopted by 윽 others. While the upper limit for the fat $A$ (van de Kamer) method $(6 \cdot 81 \mathrm{~g} /$ day $)$ is similar to that of $\mathcal{D}$ most authors, the upper limit for ${ }^{131} \mathrm{I}$-triolein is much $\mathrm{D}$ lower, and is comparable only with those of Cox (1963) and Clark et al (1964).

Comparison of the results of fat $A$ with those of fat B demonstrates a close relationship with a syste- $\vec{\theta}$ matic difference between the two methods in the abnormal range. Fat B (total lipids) gives results which are consistently higher than those of fat $\mathrm{A}$ (Fig. 5a). In the normal range variation of individual results is much larger, and the mean ratio fat $A$ : fat $B$ is lower (Fig. 5b). There is also no correlation $\mathbb{D}$ between the ${ }^{131}$ I-triolein results and either method of fat estimation in the normal group (Figs. 4a and b). Several factors may contribute to this: $(a)$ inaccura-

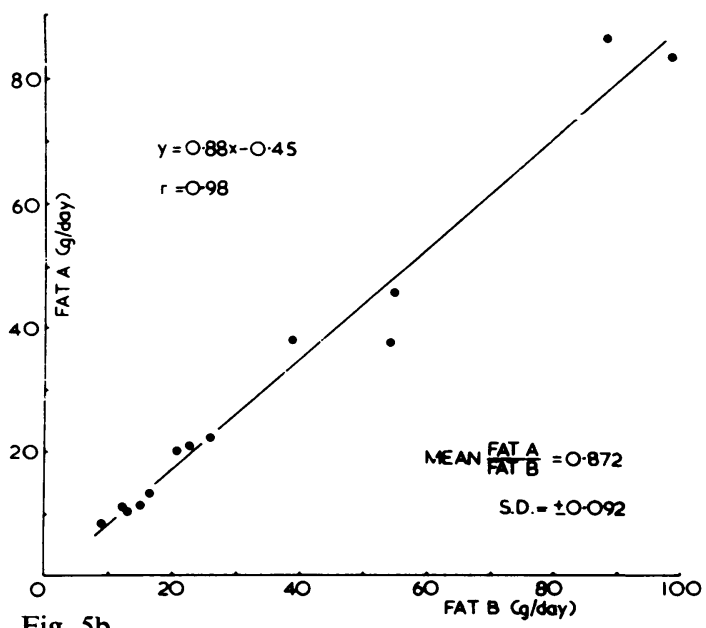

Fig. $5 b$.

Fig. 5 Relationship between fat $A$ and fat $B$ in normal (5a) and abnormal (5b) cases. 


\begin{tabular}{|c|c|c|c|c|c|c|c|}
\hline \multirow[t]{2}{*}{ Series } & \multirow[t]{2}{*}{ Year } & \multicolumn{2}{|c|}{ Number of Cases } & \multicolumn{2}{|c|}{ Number of False Results } & \multicolumn{2}{|c|}{ Number Upper Limits } \\
\hline & & Total & Steatorrhoea & Negative & Positive & $\begin{array}{l}\text { Faecal Fat } \\
\text { (g/day) }\end{array}$ & $\begin{array}{l}\text { Triolein } \\
(\% \text { dose })\end{array}$ \\
\hline Lubran and Pearson & 1958 & 26 & 9 & 1 & 3 & 6 & 5 \\
\hline Playoust, Wyatt, and Blackburn & 1959 & 48 & 12 & 0 & 4 & $6 \cdot 5$ & 3 \\
\hline Jones & 1960 & 55 & 18 & 9 & 2 & 7 & 7 \\
\hline $\operatorname{Cox}$ & 1961 & 100 & 33 & 18 & 2 & 7 & 5 \\
\hline Pimparkar et al & 1960 & 115 & 54 & 24 & 16 & 7 & 7 \\
\hline Rufin, Blahd, Nordyke, and Grossman & 1961 & 50 & 26 & 7 & 4 & $5 \cdot 7$ & 5 \\
\hline Moertel, Scudamore, Wollaeger, and Owen & 1962 & 64 & 36 & 15 & $\mathbf{0}$ & $7 \cdot 5$ & 6 \\
\hline Berkowitz, Croll, and Shapiro & 1962 & 60 & 35 & 2 & 1 & 7 & 7 \\
\hline $\begin{array}{l}\text { Rivera, Toro-Goyco, Rodriguez-Molina, } \\
\text { Coca-Mir, and Bernabe-Prida }\end{array}$ & 1962 & 66 & 42 & 6 & 4 & $\begin{array}{l}9 \% \\
\text { diet fat }\end{array}$ & 5 \\
\hline $\begin{array}{l}\text { Correia, Coelho, Godinho, Barros, and } \\
\text { Magalhaes }\end{array}$ & 1963 & 25 & 5 & 0 & 9 & $4 \cdot 7$ & $8 \cdot 7$ \\
\hline $\begin{array}{l}\text { Cox } \\
\text { Clark et al }\end{array}$ & $\begin{array}{l}1963 \\
1964\end{array}$ & $\begin{array}{r}125 \\
53\end{array}$ & $\begin{array}{l}67 \\
14\end{array}$ & $\begin{array}{r}24 \\
7\end{array}$ & $\begin{array}{l}1 \\
2\end{array}$ & $\begin{array}{l}7 \\
5\end{array}$ & $\begin{array}{l}2 \cdot 3 \\
2\end{array}$ \\
\hline Totals & & 787 & 351 & 113 & 48 & & \\
\hline Percentage & & & $44 \cdot 6$ & $\begin{array}{l}32 \cdot 2 \\
\text { of } \\
\text { steatorrh }\end{array}$ & $\begin{array}{l}11.0 \\
\text { Of } \\
\text { a non-steator }\end{array}$ & thoea & \\
\hline
\end{tabular}

Table III Results in 12 studies where chemical estimation of faecal fat was compared with radioactive absorption

cies may be large because the quantities measured are small; (b) variations of dietary fat intake may be important in relation to the composition of the small fraction excreted in normal subjects; and $(c)$ a significant part of the excreted fat may be endogenous in origin (Wollaeger, Comfort, and Osterberg, 1947, Cooke, Thomas, Mangall, and Cross, 1953; Weijers and van de Kamer, 1953).

In distinguishing between normal and abnormal degrees of fat excretion, however, the inconsistencies in the relationship between the van de Kamer method (which is the method most frequently used in routine laboratories) and the total lipid method in the normal range are not important, because outside the normal range the correlation is good. Similarly, the noncorrelationof the ${ }^{131}$ I-triolein method with either of these methods in the normal does not lessen the usefulness of the ${ }^{131}$ I-triolein method in distinguishing normal from abnormal. It is also clear that the ${ }^{131} \mathrm{I}$ triolein method is capable of quantitative discrimination over the abnormal range measured.

The radioactive triolein test measures the absorption of a specific neutral fat which has been physically altered by labelling. The basis of the test in the study of the absorption of fat in general depends upon the assumption that the iodinated triolein behaves like a typical neutral fat. To be useful in the diagnosis of fat malabsorption, however, it is only necessary for the absorption of iodinated triolein to bear a reasonably constant relationship to that of dietary fat. There is evidence that radioactive triolein fulfils this criterion (Turner, 1958; van Handel and Zilversmit, 1958). The test would be invalidated if the ${ }^{131}$ I label were split off the triolein while in the gut but available evidence suggests that this does not occur. Balint, Pendower, and Ramsey (1960) and Beres, Wenger, and Kirsner (1957) found that in laboratory conditions iodinated triolein was stable for one hour in various gastrointestinal secretions, and Cox (1961) demonstrated that the bond was relatively stable in faeces although he did show some splitting of the iodine bond when the triolein was incubated for four hours in duodenal juice. However, the exposure to the action of duodenal enzymes is likely to be considerably less than four hours.

It has been suggested that part of the faecal radioactivity after oral administration of radioactive triolein might be derived from free iodide excreted from the blood into the lower bowel after the absorption and splitting of the triolein. Several studies, however, have shown that there is no free radioactive iodine in the stools, all the radioactive material being in ether-soluble material (Ruffin et al, 1956; Mohamed and Hume, 1959).

Thus no evidence has been produced which in- 
validates the theoretical principles of the use of radioactive iodinated triolein in the assessment of fat absorption.

Radioactive triolein and faecal fat measurements have been carried out simultaneously in a number of reported studies. Following the usual practice in referring to cases with steatorrhoea as indicated by faecal fat measurement but with normal excretion of radioactive triolein as 'false negatives', and to cases with normal faecal fat but reduced triolein absorption as 'false positives', Table III shows the results in these reported series where there are sufficient data to make the comparison possible. In these results the two tests were in agreement in only $79.3 \%$ of the 787 cases studied. 'False negatives' were about three times as frequent as 'false positives'. In many of those cases where the tests showed disagreement there was only a slight abnormality and in some studies the discrepancy may have been caused by the fact that the tests measure different chemical constituents. All the series, however, had a number of cases in which the disagreement between the tests was so great as to make it probable that a technical error had been involved in the performance in one or other of the tests. It has been suggested (Lubran and Pearson, 1958; Cox, 1961) that one such error might be a failure to obtain a complete collection of the faeces.

Incomplete collection lowers both the radioactivity recovered and the estimated daily faecal fat. It may produce one of the following anomalous results.

\section{'FALSE NEGATIVE' TRIOLEIN TEST}

A small faecal loss is more likely to affect significantly the radioactive estimation than the fat measurement because the greater part of the radioactivity is usually passed in a few stools. This may produce a 'false negative' result in cases with steatorrhoea.

\section{'FALSE POSITIVE' TRIOLEIN TEST}

When the first few stools containing most of the radioactivity are faithfully collected, but then some of the later stools are lost, the faecal fat measurement will be significantly lowered while the radioactivity is relatively unaffected. Such circumstances may produce apparently 'false positive' triolein results. In fact, in this case it is the faecal fat measurement which is a 'false negative', the triolein test being nearly correct.

Of these possible results due to incomplete faecal collection, the one most frequently expected would be the first, ie, a 'false negative' faecal triolein test, because it could follow the loss of a single stool. It is perhaps significant that 'false negatives' are the $\frac{\bar{\sigma}}{-}$ commonest error reported with the triolein test.

Previous investigators were unable to test the completeness of their faecal collections. In the present $\frac{-}{-}$ study the use of a radioactive marker substance $\frac{\bar{c}}{\bar{c}}$ enabled estimations to be made of the completeness $\overrightarrow{\widetilde{D}}_{\overrightarrow{0}}$ of the collection of those stools corresponding to the $\varrho$ test dose of radioactive triolein. The validity of acs marker depends upon its nonabsorption in the gut $\overrightarrow{0}$ and upon it travelling through the gut at the samerate as unabsorbed fat. Previous work has shown $\vec{\omega}$ that neither chromium sesquioxide (Reifenstein, Albright, and Wells, 1945; Whitby and Lang, 1960; Hansky and Connell, 1962; Sassoon, 1966) nor scandium chloride (Pearson, 1966; Ogg, Pearson, 0 and Veall, 1968) is absorbed from the gastrointestinal tract. Results in this series with both scandium chloride and chromium sesquioxide indicate that ${ }^{-}$ these markers travel through the gut at very nearly $\vec{C}$ the same rate as fat in the form of triolein (Fig. 3) $\mathbb{D}$ Although there were slight differences in marker and triolein transit times in individual cases, these 3 differences were insignificant from the point of view of assessing the completeness of triolein recovery.

The patients studied were on general medical $\stackrel{\bullet}{-}$ wards and exceptional efforts to obtain complete collection were not made because it was wished too assess the percentage of routine faecal collections which were complete. However, both the patients and the ward staff knew that a special investigation was in progress and it is probable that this would $\stackrel{\odot}{\circ}$ improve routine faecal fat collections. Nevertheless $\vec{\circ}$ in only 40 out of 83 cases $(48.2 \%)$ was a complete 3 collection obtained. It is appreciated that the technique used only detected loss of stools referrable to the test dose; some of the cases in which complete recovery of isotopes was obtained could have been incomplete collections because non-isotope-con- $\exists$ taining stools were lost.

The high percentage $(52 \%)$ of incomplete faecal collections suggests a major source of error in the triolein test when it is performed on general wards. Even in metabolic units the collection cannot beo assumed to be complete. Rose (1964), using continuous chromium sesquioxide feeding as an indi- $N$ cator in calcium studies, reported incomplete $N$ faecal collections in seven out of 21 patients studied on a metabolic unit. In most published investigations ${ }^{\omega}$ of the triolein test the patients have either been on general medical wards or have been studied as out- - ? patients.

These experimental results appear to justify the ${ }_{-}^{+}$ conclusion that the ${ }^{131} \mathrm{I}$-triolein excretion test is as accurate as the direct faecal fat measurement in $\overrightarrow{\mathbb{D}}$ distinguishing normal from abnormal and in dis- $\frac{?}{8}$ criminating degrees of abnormality. Previous con- $\_$ 
fusion probably resulted from incomplete faecal collections-always a likely source of error. Both ${ }^{131}$ I-triolein and faecal fat measurement are vulnerable to error in faecal collection and it would appear to be essential to use a non-absorbable marker as a check against loss during collection. Provided that collection is complete, both methods give comparable results, and there does not seem to be a valid reason for the suspicion that ${ }^{131}$ I-triolein absorption is not closely related to total fat absorption. This being so, the ${ }^{131}$ I-triolein excretion test may commend itself again because of its inherent technical advantages.

\section{References}

Andersen, D. H. (1945). Celiac syndrome. 1 : Determination of fat in feces; reliability of two chemical methods and of microscopic estimate; excretion of feces and fecal fat in normal children. Amer. J. Dis. Child., 69, 141-151.

Balint, J., Pendower, J., and Ramsey, N. W. (1960). The stability of radio-iodinated olive oil. Clin. Sci., 19, 321-325.

Baylin, G. J., Sanders, A. P., Isley, J. K., Shingleton, W. W., Hymans, J. C., Johnston, D. H., and Ruffin, J. M. (1955). ${ }^{131}$ I Blood levels correlated with gastric emptying determined radiographically. II Fat Test Meal. Proc. Soc. exp. Biol. (N.Y.), 89, 54-56.

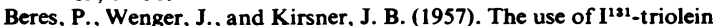
in the study of absorptive disorders in man. Gastroenterology, 32, 1-16.

Berkowitz, D., Croll, M. N., and Shapiro, B. (1962). Evaluation of radioisotopic triolein techniques in the detection of steatorrhea. Gastroenterology, 42, 572-578.

Burch, P. J. J. (1961). Gamma ray spectra in large organic scintillators. Proc. phys. Soc., 77, 1125-1132.

Clark, C. G., Crooks, J., Dawson, A. A., and Mit chell, P. E. G. (1964). The incidence of malabsorption of radiotriolein following polya partial gastrectomy in patients on a normal diet. Scot. med. J., 9, 365-373.

Cooke, W. T., Thomas, G., Mangall, D., and Cross, H. (1953). Observations of the faecal excretion of total solids, nitrogen, sodium, potassium, water and fat in the steatorrhoea syndrome. Clin. Sci., 12, 223-234.

Correia, J. P., Coelho, C. S., Godinho, F., Barros, F., and Magalhaes, E. M. (1963). Use of labeled triolein and oleic acid in the study of intestinal absorption. Amer. J. dig. Dis., 8, 649-665.

Cox, A.G.(1961). Assessment of the radiotriolein test in steatorrhoea. Brit. med. J., 2, 933-938.

Cox, A. G. (1963). Importance of the dosing procedure in the radiotriolein test for steatorrhea. Gastroenterology, 44, 275-281.

Hansky, J., and Connell, A. M. (1962). Measurement of gastrointestinal transit using radioactive chromium. Gut, 3, 187-188.

Henry, R. J. (1964). In Clinical Chemistry, Principles and Technics. Hoeber, New York.

Isley, J. K., Jr., Sanders, A. P., Baylin, G. J., Sharpe, K. W., Hymans, J. C., Ruffin, J. M., Shingleton, W. W., and Wilson, J. R., Jr. (1957). Use of $\mathbf{I}^{121}$ labelled oleic acid in study of gastrointestinal function. Proc. Soc. exp. Biol. (N.Y.), 94, 807-809.

Jones, R. V. (1960). Estimation of faecal fat. Brit. med. J., 2, 1236-1237.

Kamer, J. H., van de, Huinink, H. ten B., and Weijers, H. A. (1949). Rapid method for the determination of fat in faeces. J. Biol. Chem., 177, 347-355.

Lubran, M., and Pearson, J. D. (1958). A screening test for steatorrhoea using ${ }^{131}$ I labelled triolein. J. clin. Path., 11, 165-169.

Moertel, C. G., Scudamore, Y. H., Wollaeger, E. E., and Owen, C. A., Jr. (1962). Limitations of the $I^{131}$-labeled triolein tests in the diagnosis of steatorrhea. Gastroenterology, 42, 16-21.

Mohamed, S. D., and Hume, R. (1959). Radioiodinated triolein in malabsorption states. J. clin. Path., 12, 535-540.

Ogg, C.S., Pearson, J. D., and Veall, N. (1968). A method for measuring the gastro-intestinal absorption of ${ }^{47} \mathrm{Ca}$ using ${ }^{47} \mathrm{Sc}$ as an inert marker. Clin. Sci., 34, 327-332.
Pearson, J. D. (1966). Use of ${ }^{61} \mathrm{Cr}$-labelled haemoglobin and ${ }^{17} \mathrm{Sc}$ as inert faecal markers. Int. J. appl. Radiat., 17, 13-16.

Pimparkar, B. D., Tulsky, E. G., Kalser, M. H., and Bockus, H. L. (1960). Correlation of radioactive and chemical faecal fat in different malabsorption syndromes. Brit. med. J., 2, 894-900.

Playoust, M. R., Wyatt, J. V., and Blackburn, C. R. B. (1959) Studies in fat absorption. III. The radiotriolein and radio-oleic acid absorption tests. Aust. Ann. Med., 8, 245-51.

Reifenstein, E. C., Jr., Albright, F., and Wells, S. L. (1945). The accumulation, interpretation and presentation of data pertaining to metabolic balances, notably those of calcium, phosphorus, and nitrogen. J. clin. Endocr., 5, 367-395.

Rivera, J. V., Toro-Goyco, E., Rodríguez-Molina,R., Coca-Mir, R. and Bernabe-Prida, R. (1962). The triolein absorption test in the diagnosis of steatorrhea. Gastroenterology, 43, 13-23.

Rose, G. A. (1964). Experiences with the use of interrupted carmine red and continuous chromium sesquioxide marking of human faeces with reference to calcium, phosphorus, and magnesium. Gut, 5, 274-279.

Ruffin, J. M., Shingleton, W. W., Baylin, G. J., Hymans, J. C., Isley, J. K., Sanders, A. P., and Sohmer, M. F., Jr. (1956). $I^{131}$-labeled fat in the study of intestinal absorption. New Engl. J. Med., 255, 594-597.

Ruffin, J. M., Keever, I. C., Chears, C., Jr., Shingleton, W. W. Baylin, G. J., Isley, J. K., and Sanders, A. P. (1958). Further observations on the use of I $^{131}$-labeled lipids in the study of diseases of the gastrointestinal tract. Gastroenterology, 34, 484-490.

Rufin, F., Blahd, W. H., Nordyke, R. A., and Grossman, M. I. (1961). Reliability of $\mathbf{I}^{131}$-triolein test in the detection of steatorrhea. Gastroenterology, 41, 220-224.

Sassoon, H. F. (1966). Labelled chromium sesquioxide as a marker for digesta: preparation and quantitative determination in faeces. Int. J. appl. Radiat., 17, 329-334.

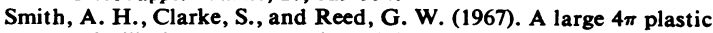
scintillation detector with clinical applications. Int. J. appl. Radiat., 18, 647-652.

Stanley, M. M., and Thannhauser, S. J. (1949). The absorption and disposition of orally administered $I^{131}$-labeled neutral fat in man. J. Lab. clin. Med., 34, 1634-1639.

Turner, D. A. (1958). The absorption, transport and deposition of fat. Amer. J. Dig. Dis., 3, 594-640.

Weijers, H. A., and Kamer, J. H. van de (1953). Coeliac disease. I. Criticism of the various methods of investigation. Acte paediat. (Uppsala), 42, 24-33.

Vidinli, M., Texter, E. C., Jr., and Cooper, J. A. D. (1963). The I'1. triolein absorption test. Amer. J. dig. Dis., 8, 742-762.

van Handel, E., and Zilversmit, D. B. (1958). Limitation of radioiodine as a label for fat. J. Lab. clin. Med., 52, 831-839.

Whitby, L. G., and Lang, D. (1960). Experience with the chromic oxide method of fecal marking in metabolic balance investigations on humans. J. clin. Invest., 39, 854-863.

Wollaeger, E. E., Comfort, M. W., and Osterberg, A. E. (1947) Total solids, fat and nitrogen in the feces: III. A study of normal persons taking a test diet cont aining a modera te amount of fat, comparison with results obtained with normal persons taking a test diet containing a large amount of fat. Gastroenterology, 9, 272-283.

Zuckerman, J. L., Zymaris, M. C., and Natelson, S. (1949). A simple method for the determination of fecal fat and fatty acids. $J$. Lab. clin. Med., 34, 282-286.

\section{Appendix}

The $\gamma$-ray resolution of a plastic phosphor is inferior to that of a sodium iodide crystal mainly because of the low specific light output and the general predominance of Compton over photoelectric interactions (Burch, 1961). The measurement of two isotopes simultaneously is therefore more difficult as a broad energy window has normally to be used.

When ${ }^{51} \mathrm{Cr}$-chromium sesquioxide was used as the faecal marker, the windows used were from 500 
to $750 \mathrm{kev}$ (utilizing the higher $\gamma$-ray energy of $\left.{ }^{131} \mathrm{I}\right)$ and from 250 to $400 \mathrm{kev}$. Unfortunately the latter condition envelopes both the chromium $\gamma$-ray energy and the most abundant ${ }^{131}$ I $\gamma$-ray energy so that the iodine contribution to the total counts recorded in this window was large. It was also found that under high count rate conditions pulse summation occurred which produced a higher count rate in the upper energy window than that due solely to the iodine content of the sample and was dependent upon the total activity in the sample. When scandium chloride was substituted for chromium sesquioxide as the faecal marker the operating conditions were changed to a window setting between 1.0 and $1.2 \mathrm{Mev}$ and to an integral setting with a lower level of $250 \mathrm{kev}$. The latter setting measures both the ${ }^{131} \mathrm{I}$ and ${ }^{46} \mathrm{Sc}$ contents of the sample but it was found to be the setting which yielded the most accurate results at high count rates. Using samples of known activity it was found that the ${ }^{131}$ I content of a sample could be determined with an error of less than $10 \%$ provided that the scandium activity was less than twice the iodine activity in a sample. The minimum measurable quantity of either isotope was less than $1 \%$ of the administered dose.

\section{Reports and Bulletins prepared by the Association of Clinical Biochemists}

The following reports and bulletins are published by the Association of Clinical Biochemists. They may be obtained from The Administrative Office, Association of Clinical Biochemists, 7 Warwick Court, Holborn, London, WC1R 5DP. The prices include postage, but airmail will be charged extra. Overseas readers should remit by British Postal or Money Order. If this is not possible the equivalent of 50p is the minimum amount that can be accepted.

SCIENTIFIC REPORTS

3 Automatic Dispensing Pipettes. An assessment of 35 commercial instruments 1967 P. M. G. BROUGHTON, A. H. GOWENLOCK, G. M. WIDDOWSON, and K. A. AHLQUIST $85 \mathrm{p}(\$ 2)$

4 An Evaluation of five Commercial Flame Photometers suitable for the Simultaneous Determination of Sodium and Potassium March 1970 P. M. G. BROUGHTON and J. B. DAWSON $85 p(\$ 2)$

SCIENTIFIC REVIEWS

1 The Assessment of Thyroid Function March 1971 F. V. FLYNN and J. R. HOBBS $62 \frac{1}{2} p(\$ 1.50)$

TECHNICAL BULLETINS

9 Determination of Urea by AutoAnalyzer November

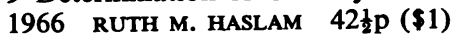

11 Determination of Serum Albumin by AutoAnalyzer using Bromocresol Green October 1967 B. E. NORTHAM and G. M. WIDDOwson $42 \frac{1}{2} \mathrm{p}(\$ 1)$

13 An Assessment of the Technicon Type II Sampler Unit March 1968 B. C. GRAY AND G. K. MCGOWAN

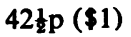

14 Atomic Absorption Spectroscopy. An outline of its principles and a guide to the selection of instruments May 1968 J. B. DAWSON and P. M. G. BROLGHTON $42 \frac{1}{2} p(\$ 1)$
15 A Guide to Automatic Pipettes (2nd edition) June 1968 P. M. G. BROUGHTON $42 \frac{1}{2} \mathrm{p}(\$ 1)$

16 A Guide to Automation in Clinical Chemistry May

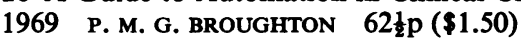

17 Flame Photometers (2nd edition) 1969 P. WILDINC $62 \frac{1}{2} \mathrm{p}(\$ 1.50)$

18 Control Solutions for Clinical Biochemistry (4th edition) March 1970 P. M. G. BROUGHTON $62 \frac{1}{2} \mathrm{p}$ (\$1.50)

19 Spectrophotometers. A comparative list of low-priced instruments readily available in Britain May $1970 \delta$ C. E. WILDE and P. SEWELL $62 \frac{1}{2} p(\$ 1.50)$

20 Quantities and Units in Clinical Biochemistry June 1970 P. M. G. BRoưhton $62 \frac{1}{2} \mathrm{p}(\$ 1.50)$ More than $\frac{\text { O }}{O}$ 30 copies in units of 10 at $20 \mathrm{p}$

21 Filter Fluorimeters: A comparative list of 18 instruments September 1970 H. BRAUNSBERG and s. $s$. $N$ BROWN $62 \frac{1}{2} \mathrm{p}(\$ 1.50)$

22 Bilirubin standards and the Determination of Bilirubin by Manual and Technicon AutoAnalyzer Methods. $\bullet$ January 1971 BARBARA BILLING, RUTH HALSAM, and $\mathbb{\Phi}$ N. WALD $62 \frac{1}{2} \mathrm{p}(\$ 1.50)$

23 Interchangeable Cells for Spectrophotometers and Fluorimeters September 1971 E. S. BROWN and A. H. GOWENLOCK $62 \frac{1}{2} \mathrm{p}(\$ 1.50)$ 